\title{
Breastfeeding counseling and support are associated with continuous exclusive breastfeeding from one week to six months of age among HIV exposed infants in north Gondar zone, Ethiopia: a cross-sectional study
}

Haregeweyin Genetu', Melaku Kindie Yenit ${ }^{1}$ and Amare Tariku ${ }^{3^{*}}$ (D)

\begin{abstract}
Background: Globally, exclusive breastfeeding prevents 1.3 million child deaths and has an added benefit for people living with the Human Immune Deficiency Virus (HIV) by preventing mother-to-child transmission of HIV. However, literature is scarce in Ethiopia; therefore this study aimed to assess the rate of continuous exclusive breastfeeding from the end of the first week to 6 months of age, among HIV exposed infants (aged 7-20 months) who were followed up in government hospitals of North Gondar Zone, Ethiopia, and associated factors.

Methods: An institutional based cross-sectional study was conducted from February 21 to March 30, 2016. All mother-child pairs (367) attending the chronic HIV care clinic in government hospitals of North Gondar Zone were included in the study. Exclusive breastfeeding was defined as the practice of feeding only breast milk (including expressed breast milk) during the first 6 months and no other liquids and solid foods except medications. However since prelacteal feeding is a deep rooted norm in the study setting, we report continuous exclusive breastfeeding from the end of first week to 6 months of age of infants, ignoring all prelacteal feeding offered at birth. A binary multivariable logistic regression analysis was employed to identify factors associated with exclusive breastfeeding.

Results: The overall prevalence of continuous exclusive breastfeeding among HIV exposed infants was 86.4\%. According to the multivariable analysis; breastfeeding counseling (Adjusted Odds Ratio $[A O R]=5.1,95 \%$ Confidence Interval $[\mathrm{Cl}] 1.4,18.2$ ), breastfeeding support ( $\mathrm{AOR}=3.7,95 \% \mathrm{Cl} 1.3,10.5)$, and not experiencing obstetric problems ( $A O R=3.4,95 \% \mathrm{Cl}: 1.3,8.8)$ were associated with higher odds of continuous breastfeeding.

Conclusions: In this study, most HIV exposed infants were continuously breastfed from the end of first week to 6 months of age. Breastfeeding counseling, breastfeeding support and experiencing obstetric problems were identified as significant determinants of continuous breastfeeding. Therefore, breastfeeding counseling and support should be strengthened to improve the coverage of optimal exclusive breastfeeding practice. Moreover, prompt diagnosis and treatment of obstetric problems should be initiated.
\end{abstract}

Keywords: Continuous exclusive breastfeeding, Exposed infants, Breastfeeding counseling, Breastfeeding support, Ethiopia

\footnotetext{
* Correspondence: amaretariku15@yahoo.com

${ }^{3}$ Department of Human Nutrition, College of Medicine and Health Sciences,

Institute of Public Health, University of Gondar, Gondar, Ethiopia

Full list of author information is available at the end of the article
} 


\section{Background}

Breastfeeding is an essential child survival intervention and provides immunological, psychological, and socioeconomic benefits [1-3]. Globally, exclusive breastfeeding prevents 1.3 million child deaths [4]. In the era of the Human Immune Deficiency Virus (HIV) pandemic, breastfeeding is considered as a source of mother-tochild transmission of $\operatorname{HIV}[1,5,6]$. As a result, the World Health Organization (WHO) advised mothers infected with HIV to avoid breastfeeding if they were able to afford and safely prepare formula milk [7]. However, mindful of the growing evidence supporting the benefits of EBF, the WHO now recommends HIV positive mothers to exclusively breastfed their infant's for 6 months, and to take antiretroviral drugs throughout the breastfeeding period and until the child is 12 months of age, to reduce the risk of HIV transmission [6-9].

In spite of this fact, not exclusively breastfeeding continues as a global public health problem, and only 39\% of infants are exclusively breastfed [10, 11]. In particular, mixed feeding is still practiced as the norm in developing countries, and it is found to increase the risk of child deaths from under-nutrition, diarrhea, pneumonia and other morbidities [10]. There is a marked regional variation; about $24-80 \%$ of infants exposed to HIV are exclusively breastfed in Africa [11-18]. According to the Ethiopian Demographic and Health Survey (EDHS) Report (2011), about 51\% of mothers practice EBF [19]. However, some improvements are observed among HIV infected mothers, and the prevalence of EBF is modest in Addis Ababa [20] and West Oromia (68 and 72\%, respectively) [21], while it is highest in Gondar (89.5\%) [22] and Mekele (90\%) [11]. However, the prevalence of exclusive breastfeeding in Southern Ethiopia is even lower than the national average of 48\% [7].

Studies have demonstrated that exclusive breastfeeding affected by various factors. The mother's age [20], knowledge on the benefit of exclusive breastfeeding [12, 23], occupation [7, 12, 20, 22], urban or rural residence [24], lack of education [20], income [20], and the high cost of formula milk [13] are some the sociodemographic factors significantly associated with exclusive breastfeeding. It is also strongly related to the level of maternal healthcare utilization and morbidities, accordingly the mode and place of delivery [18, 20, 22, 25], prenatal [20] and postnatal healthcare utilization [20], receiving infant feeding counseling [20, 25, 26], breastfeeding support $[20,22]$, facing obstetric complications and other maternal morbidities [20, 25] and history of infant illness in the first 6 months $[20,27]$ are correlated with EBF. Among the psychosocial determinants, fear of stigma and discrimination $[9,14,25]$ and use of herbal medicines [25] are inversely related with exclusive breastfeeding.
In Ethiopia about $1.5 \%$ of adults (15-49 years) are HIV positive and the prevalence is higher among women (1.9\%) [19]. To reduce the risk of mother-to-child transmission of HIV and AIDS related child mortality, the country designed a guideline which advocates exclusive breastfeeding for the first 6 months, though the practice remains sub-optimal [20-22, 27]. Exclusive breastfeeding among HIV positive mothers is not well investigated; the available studies have been conducted on urban dwellers $[20,22,27]$, while poorer child feeding practice, lower literacy rate and maternal health care utilization are documented in the rural inhabitants [19]. Therefore this study aimed to determine the prevalence of continuous exclusive breastfeeding and associated factors from the end of first week to 6 months of age among HIV exposed infants (7-20 months) who had follow up in government hospitals of North Gondar Zone, Ethiopia.

\section{Methods \\ Study setting and design}

An institutional based cross-sectional study was conducted from 21 February to 30 March 2016 in the three hospitals of North Gondar Zone, northwest Ethiopia. The zone has 126 health centers and 6 hospitals providing health services to the community. Among the total six hospitals in the study area, only three (Metema Hospital, Dabark Hospital and Gondar University Hospital) are currently providing Anti-Retro Viral Treatment (ART) and Prevention of Mother to Child Transmission (PMTCT) of HIV services. A total of 392 HIV infected mothers with children aged 7-20 months were registered for HIV care and support.

\section{Sample size and sampling procedure}

All HIV positive mothers who had a child aged between 7 and 20 months and attended the chronic HIV care clinic were the population under study. Mother-child pairs were recruited from the three public hospitals providing HIV care in North Gondar Zone. The sample size was calculated using Epi-Info version 3.7 by considering the following assumptions; the prevalence of EBF among HIV exposed infants was $68 \%$ [20], 95\% level of confidence, 5\% margin of error, and $10 \%$ non-response rate. Finally, the minimum sample size of 367 was obtained. To employ the systematic random sampling technique, a sampling fraction $\left(K^{\text {th }}=N / n\right)$ was computed by dividing the total number of mother-child pairs enrolled for HIV care in the three hospitals to the total sample size, and it was 1.07. As a result, all eligible motherchild pairs attending the hospitals during the study period were included consecutively. 


\section{Data collection procedure}

A structured interviewer-administered questionnaire was used to collect data. To maintain consistency, the questionnaire was first translated from English to Amharic (the native language of the study area) and was retranslated to English by professional translators and Public Health experts. Six clinical nurses as data collectors and two health officers as supervisors were recruited for the study. Two days intensive training regarding the objective of the study, confidentiality of information, and techniques to conduct interview was given to the data collectors and supervisors.

To address the ethical issues, the data collectors were recruited among the permanent employees of the respective hospitals. The data collectors might be prone to commit social desirability bias, and efforts were made to equip the data collectors with techniques to minimize this risk. Accordingly, all the study participants were informed about the objective of the study. The study was not aimed to evaluate their adherence to counseling and treatment, and their response would not affect their treatment. Moreover, data collectors created a conducive environment by keeping the mothers apart and making them comfortable during data collection. For a few mothers who faced difficulties in remembering the right time of cessation of EBF, data collectors carried out different probing mechanisms to help them to recall, thereby minimizing recall bias. Relating the time of initiation of additional (complementary) food to known public events and immunization schedules were some of the probing techniques used by data collectors.

The questionnaire was also piloted on $5 \%$ of the total sample out of the study area and the acceptability and applicability of the procedures and tools were evaluated during pretest.

\section{Data analysis and study variables}

According to the WHO criteria, exclusive breastfeeding is defined as the practice of feeding only breast milk (including expressed breast milk) during the first 6 months and no other liquids and solid foods except medications [28]. Accordingly, we asked mothers the question "When did you first introduce any solid, semisolid, or fluid (including water) to [child's name] in addition to breast milk". However, prelacteal feeding is widely practiced in the study area [19]. Therefore, using a lifelong indicator would underestimate the proportion of infants being exclusively breastfed. We decided to excluded anything given to the infant in the first 2-3 days of life (prelacteal feeding) [29]. Therefore, this study determined the continuous exclusive breastfeeding period from the end of first week to 6 months of age among HIV exposed infants (aged 7-20 months) who had follow up in government hospitals of North Gondar Zone.
Eleven questions were used to determine the mother's Infant and Young Child Feeding (IYCF) knowledge. Mothers were asked about the modes of mother to child transmission of HIV, benefit of breastfeeding, timely initiation of breastfeeding, colostrum feeding and it's health benefit, optimal duration of exclusive breastfeeding, timely initiation of complementary feeding, type of food to start complementary feeding, how to feed a child and optimal duration of continued breastfeeding. Using Principal Component Analysis (PCA), the factor scores were summed and ranked to terciles as lowest, medium and highest. Likewise, the household wealth status was computed using a composite indicator for urban and rural residents by considering household assets and size of agricultural land. PCA was performed to define the household wealth status into lowest, middle and highest.

Data were entered into Epi-Info version 3.5.3 and exported to Statistical Package for Social Sciences (SPSS) version 20 for further analysis. Data cleaning was done by running frequencies. Descriptive statistics, including frequencies and proportions were computed to summarize variables. A binary logistic regression model was fitted. Both bivariable and multivariable logistic regression analyses were done, and variables with a $p$-value of $<0.2$ in the bivariable analysis were subjected to the multivariable analysis. Both Crude Odds Ratio (COR) and Adjusted Odds Ratio (AOR) with a 95\% Confidence Interval (CI) were estimated to show the strength of association. A $p$-value of $<0.05$ was used to identify variables that showed statistical significance in the multivariable analysis.

\section{Results}

A total of 367 mother-child pairs were included in the study. The mean ( \pm Standard Deviation, SD) age of the mothers and the children was $31.3( \pm 4.4)$ years and 12.9 $( \pm 4.1)$ months, respectively. In this study, about threefourths of the mothers $(74.9,77.7$ and $82.3 \%$, respectively) were married, urban inhabitants, and aged 20-35 years. Nearly half $(44.8 \%)$ of mothers were outdoor workers (Table 1).

A substantial proportion (96.5\%) of mothers had at least one antenatal care visit, of which $94.6 \%$ were counseled about EBF. Almost all (97.3\%) of respondents gave birth at healthcare institutions; and cesarean-section delivery was reported by $21.5 \%$. About $47.4 \%$ of mothers had an obstetric problem (Table 2). Despite efforts to prevent mother-to-child transmission of HIV, about $1.9 \%$ of exposed infants were HIV positive. All (100\%) of the HIV infected children were from mothers who did not receive any breastfeeding support and gave birth virginally. A higher proportion of HIV infection was noted among children who were given prelacteal feeds, whose mothers were illiterate $(71.4 \%)$ and who experienced an obstetric problem (57.1\%) (Table 3). 
Table 1 Sociodemographic and economic characteristics of HIV positive mothers with children aged 7 to 20 months attending public hospitals in North Gondar Zone, Ethiopia, $2016(n=367)$

\begin{tabular}{|c|c|c|}
\hline Variables & Frequency & Percentag \\
\hline \multicolumn{3}{|l|}{ Child sex } \\
\hline Male & 193 & 52.6 \\
\hline Female & 174 & 47.4 \\
\hline \multicolumn{3}{|l|}{ Child age } \\
\hline 7-12 months & 185 & 50.4 \\
\hline $13-20$ months & 182 & 49.6 \\
\hline \multicolumn{3}{|c|}{ Mean $( \pm S D)$ age $12.9( \pm 4.1)$ months } \\
\hline \multicolumn{3}{|l|}{ Maternal age } \\
\hline 20-35 years & 302 & 82.3 \\
\hline $36-43$ years & 65 & 17.7 \\
\hline \multicolumn{3}{|c|}{ Mean \pm SD for mothers was $31.3( \pm 4.4)$ years } \\
\hline \multicolumn{3}{|l|}{ Number of parity } \\
\hline $1-3$ & 325 & 88.6 \\
\hline $4-6$ & 42 & 11.4 \\
\hline \multicolumn{3}{|c|}{ Number of under five children } \\
\hline 1 & 242 & 65.9 \\
\hline$>1$ & 125 & 34.1 \\
\hline \multicolumn{3}{|l|}{ Family size } \\
\hline$\leq 5$ & 269 & 73.3 \\
\hline$>5$ & 98 & 26.7 \\
\hline \multicolumn{3}{|l|}{ Residence } \\
\hline Urban & 285 & 77.7 \\
\hline Rural & 82 & 22.3 \\
\hline \multicolumn{3}{|l|}{ Marital status } \\
\hline Currently married & 275 & 74.9 \\
\hline Currently unmarried $^{c}$ & 92 & 25.1 \\
\hline \multicolumn{3}{|l|}{ Religion } \\
\hline Orthodox & 296 & 80.7 \\
\hline Muslim & 52 & 14.2 \\
\hline Protestant & 19 & 5.1 \\
\hline \multicolumn{3}{|l|}{ Ethnicity } \\
\hline Amhara & 286 & 77.9 \\
\hline Kemant & 62 & 16.9 \\
\hline Tigre & 12 & 3.3 \\
\hline Oromo & 7 & 1.9 \\
\hline \multicolumn{3}{|l|}{ Wealth status } \\
\hline Poor & 122 & 33.3 \\
\hline Medium & 130 & 35.4 \\
\hline Rich & 115 & 31.3 \\
\hline \multicolumn{3}{|l|}{ Maternal education } \\
\hline Illiterate & 110 & 30 \\
\hline Literate & 257 & 70 \\
\hline
\end{tabular}

Table 1 Sociodemographic and economic characteristics of HIV positive mothers with children aged 7 to 20 months attending public hospitals in North Gondar Zone, Ethiopia, $2016(n=367)$ (Continued)

\begin{tabular}{|c|c|c|}
\hline \multicolumn{3}{|l|}{ Paternal education } \\
\hline Illiterate & 48 & 13.1 \\
\hline Literate & 319 & 86.9 \\
\hline \multicolumn{3}{|c|}{ Maternal employment } \\
\hline Employee $^{b}$ & 96 & 26.2 \\
\hline Housewife & 166 & 45.2 \\
\hline Outdoor workers $^{\mathrm{a}}$ & 105 & 28.6 \\
\hline \multicolumn{3}{|c|}{ Paternal employment } \\
\hline Employee $^{\mathrm{b}}$ & 149 & 40.6 \\
\hline Outdoor workers $^{\mathrm{a}}$ & 218 & 59.4 \\
\hline
\end{tabular}

${ }^{\mathrm{a} M e r c h a n t s ~ a n d ~ d a i l y ~ l a b o r e r s ~}$

${ }^{\mathrm{b}}$ Governmental and non-governmental employees

csingle, divorced, and widowed

The study demonstrated that, about $86.4 \%$ (95\% CI: $82.9,89.9 \%$ ) of HIV exposed infants were continuously exclusively breastfed from the end of first week to 6 months of age. Two-thirds (72.8\%) of mothers initiated breastfeeding within an hour of delivery, and about $79.6 \%$ of infants were given colostrum. However, prelacteal feeding was given to $19.1 \%$ of infants (Table 4).

Both bivariable and multivariable analyses were done to identify factors associated with continuous exclusive breastfeeding. Accordingly, the result of bivariable analysis noted that counseling about exclusive breastfeeding, colostrum feeding, experiencing an obstetric problem, decision to breastfeed, breastfeeding support, place of delivery, and infant illness were significantly associated with the practice of continuous exclusive breastfeeding. However, only breastfeeding support, breastfeeding counseling, and experiencing an obstetric problem remained significantly and independently associated with exclusive breastfeeding in the multivariable analysis. Consequently, the odds of continuous EBF were higher among HIV infected mothers who received prenatal EBF counseling $(\mathrm{AOR}=5.1 ; 95 \% \mathrm{CI}: 1.4,18.2)$ compared to those who did not receive counseling. Similarly, obtaining breastfeeding support (AOR $=3.7,95 \% \mathrm{CI}: 1.3,10.5)$ and not experiencing an obstetric problem (AOR $=3.4,95 \% \mathrm{CI}$ : $1.3,8.8)$ were associated with increased odds of mothers with a continuous exclusive breastfeeding practice (Table 5).

\section{Discussion}

Exclusive breastfeeding has been considered as one of the proven child survival interventions [10, 30]. Ethiopia has adopted these established facts and set a target to improve EBF to $70 \%$ by 2020 [31]. This study showed that, the prevalence of continuous EBF among infants exposed to HIV was $86.4 \%$ which was higher than the 
Table 2 Healthcare utilization and morbidity related characteristics of HIV positive mothers with children aged 7 to 20 months attending public hospitals in North Gondar Zone, Ethiopia, $2016(n=367)$

\begin{tabular}{lll}
\hline Variables & Frequency & Percentage \\
\hline Antenatal care visit & & \\
Yes & 354 & 96.5 \\
No & 13 & 3.5
\end{tabular}

Number of antenatal care visits

$1-3$

$\geq 4$

Counseling about infant feeding

Yes

No

Counseling about exclusive breastfeeding

Yes

347

No

20

Place of delivery

Health institution

357

Home

10

Gestational age

Preterm

Term

Post term

Mode of delivery

Spontaneous vaginal

Assisted vaginal delivery

Cesarean section

History of obstetrics problem

Yes

No

Type of obstetric problem

Prolonged labor

Ante partum hemorrhage

Postpartum hemorrhage

Others $^{a}$

Breast problem

Yes

No

Child weight

$2.5-3.0 \mathrm{~kg}$

$>3.0 \mathrm{~kg}$

Not recorded

Disclosing HIV status

Yes

No

58

For whom HIV status disclosed ${ }^{b}$
Table 2 Healthcare utilization and morbidity related characteristics of HIV positive mothers with children aged 7 to 20 months attending public hospitals in North Gondar Zone, Ethiopia, $2016(n=367)$ (Continued)

\begin{tabular}{|c|c|c|}
\hline Spouse & 261 & 71.1 \\
\hline Family & 219 & 59.6 \\
\hline Community & 16 & 4.4 \\
\hline Friend & 53 & 14.4 \\
\hline Others & 32 & 8.4 \\
\hline \multicolumn{3}{|l|}{ Postnatal care } \\
\hline Yes & 266 & 72.5 \\
\hline No & 101 & 27.5 \\
\hline \multicolumn{3}{|c|}{ History of infanthood morbidity } \\
\hline Yes & 120 & 32.7 \\
\hline No & 247 & 67.3 \\
\hline \multicolumn{3}{|l|}{ Healthcare access } \\
\hline$\leq 2 \mathrm{~h}$ & 233 & 63.5 \\
\hline$>2 \mathrm{~h}$ & 134 & 36.5 \\
\hline \multicolumn{3}{|c|}{ Breastfeeding support received } \\
\hline Yes & 317 & 90.6 \\
\hline No & 33 & 9.4 \\
\hline \multicolumn{3}{|c|}{ Source of breastfeeding support } \\
\hline Spouse & 251 & 68.4 \\
\hline Family & 286 & 78.8 \\
\hline Community $^{c}$ & 1 & 0.3 \\
\hline Friends & 85 & 23.2 \\
\hline Health professionals & 222 & 60.5 \\
\hline \multicolumn{3}{|c|}{ Mothers decide to breastfeed } \\
\hline Yes & 325 & 88.6 \\
\hline No & 42 & 11.4 \\
\hline
\end{tabular}

national target. The finding was also consistent with other reports from Ethiopia: Gondar (89.5\%) [22] and Mekele (90\%) [31]. This might be related to the contextual similarities in maternal healthcare utilization among study settings.

However, the prevalence of continuous EBF was higher than what was reported from Addis Ababa (68\%) [20], Southern Ethiopia (48\%) and West Oromia (72\%) [21]. The observed discrepancy might be attributed to efforts made by the government in promoting the optimal child feeding practice for HIV infected mothers mainly in the PMTCT, exposed infant, and ART clinics [32, 33]. Likewise, the finding was higher than the reports of other developing countries, such as India (44\%) [34], Tanzania (24-46\%) [16], Kenya (80.4\%) [15], Ghana (60\%) [13] and Nigeria (61\%) [14]. This is probably due to the fact 
Table 3 Distribution of child HIV status by the selected maternal characteristics in North Gondar Zone public hospitals, Ethiopia

\begin{tabular}{|c|c|c|}
\hline \multirow[t]{2}{*}{ Variables } & \multicolumn{2}{|c|}{ HIV status of the child } \\
\hline & Positive \# (\%) & Negative \# (\%) \\
\hline \multicolumn{3}{|c|}{ Prelacteal feeding } \\
\hline Yes & $4(57.1)$ & $66(18.3)$ \\
\hline No & $3(42.9)$ & $294(81.7)$ \\
\hline \multicolumn{3}{|c|}{ Mother's education } \\
\hline Illiterate & $5(71.4)$ & $105(29.2)$ \\
\hline Literate & $2(28.6)$ & $255(70.8)$ \\
\hline \multicolumn{3}{|c|}{$\begin{array}{l}\text { Counseling about exclusive } \\
\text { breastfeeding }\end{array}$} \\
\hline Yes & $0(0)$ & $347(96.4)$ \\
\hline No & $7(100.0)$ & $13(3.6)$ \\
\hline \multicolumn{3}{|l|}{ Mode of delivery } \\
\hline Vaginal delivery & $7(100.0)$ & $167(46.4)$ \\
\hline Others $^{a}$ & $0(0)$ & $193(43.6)$ \\
\hline \multicolumn{3}{|c|}{ History of obstetric problem } \\
\hline Yes & $4(57.1)$ & $170(47.2)$ \\
\hline No & $3(42.9)$ & $190(42.8)$ \\
\hline
\end{tabular}

that, there is higher cultural acceptability of breastfeeding in this study area. Furthermore, the difference in EBF practice could be related to the variations in the study design. The later studies employed a cohort study design and ascertained exclusive breastfeeding practice prospectively [15, 34], while this study measured EBF retrospectively using a cross-sectional study design. Therefore, the increased prevalence of EBF in the current study could be related to the retrospective ascertainment of the EBF practice [29].

The result of the adjusted analysis showed that, the odds of continuous exclusive breastfeeding were higher among mothers who received prenatal EBF counseling. The finding was supported by reports elsewhere $[14,17,26,35,36]$. In fact, birth preparedness and breastfeeding counseling are important components of prenatal care, and the repeated visits also help to bring the intended maternal behavioral change towards the optimal breastfeeding practice. The impact of prenatal care mainly operates through the role of clinicians in providing the correct and up-to-dated IYCF information to the mothers [35, 37]. In Ethiopia, implementation of the urban Health Extension Program steps-up utilization of antenatal care, which creates an extra benefit in bringing the promotive health services, including breastfeeding counseling to the household level [30, 38].

Similarly, the higher odds of continuous exclusive breastfeeding were reported among mothers who had no history of obstetric problems. The finding was consistent
Table 4 Breastfeeding practice of children aged 7 to 20 months attending public hospitals in North Gondar Zone, Ethiopia, 2016 $(n=367)$

\begin{tabular}{|c|c|c|}
\hline Variables & Frequency & Percentage \\
\hline \multicolumn{3}{|c|}{ Continuous exclusive breastfeeding } \\
\hline Yes & 317 & 86.4 \\
\hline No & 50 & 13.6 \\
\hline \multicolumn{3}{|l|}{ Ever breastfed } \\
\hline Yes & 352 & 95.9 \\
\hline No & 15 & 4.1 \\
\hline \multicolumn{3}{|c|}{ Reasons for not breastfeeding $(n=15)$} \\
\hline Shortage of breast milk & 2 & 13.3 \\
\hline Mother was busy & 7 & 46.7 \\
\hline Not willing to breastfeed & 2 & 13.3 \\
\hline Health problem of the mother & 3 & 20 \\
\hline Health problem of the child & 1 & 6.7 \\
\hline \multicolumn{3}{|l|}{ Colostrum given } \\
\hline Yes & 292 & 79.6 \\
\hline No & 75 & 20.4 \\
\hline \multicolumn{3}{|l|}{ Prelacteal feeding } \\
\hline Yes & 70 & 19.1 \\
\hline No & 297 & 80.9 \\
\hline \multicolumn{3}{|l|}{ Type of prelacteal food given ${ }^{a}$} \\
\hline Butter & 8 & 11.4 \\
\hline Plain water & 25 & 35.7 \\
\hline Sugar with water & 40 & 57.1 \\
\hline Abesh $^{\mathrm{b}}$ & 11 & 15.7 \\
\hline Traditional medicine & 7 & 10 \\
\hline \multicolumn{3}{|c|}{ Frequency of breastfeeding per day } \\
\hline$\geq 8$ times & 317 & 90.1 \\
\hline$<8$ times & 35 & 9.9 \\
\hline \multicolumn{3}{|l|}{ Initiation of breastfeeding } \\
\hline Within $1 \mathrm{~h}$ & 254 & 72.8 \\
\hline After $1 \mathrm{~h}$ & 95 & 27.2 \\
\hline \multicolumn{3}{|l|}{ Mothers IYCF knowledge } \\
\hline Good & 136 & 37 \\
\hline Medium & 132 & 36 \\
\hline Poor & 99 & 27 \\
\hline
\end{tabular}

${ }^{\text {a }}$ Multiple responses

${ }^{\mathrm{b}}$ Abesh is made from a roosted fenugreek which is powdered, fermented, and diluted with water

with the report from Addis Ababa [20]. The possible explanation might be attributed to the psychological effects of obstetric problems, such as depression, lack of confidence or worry leading to delayed initiation of breastfeeding. In fact, the delayed initiation of breastfeeding was found to negatively affect the duration of EBF [39]. Moreover, when mothers encountered obstetrics problems, 
Table 5 Factors associated with continuous EBF among HIV positive mothers with children aged 7 to 20 months attending public hospitals in North Gondar Zone, Ethiopia, $2016(n=367)$

\begin{tabular}{lllll}
\hline Variables & $\mathrm{EBF}^{\mathrm{a}}$ & $\mathrm{COR}^{\mathrm{b}}(95 \% \mathrm{Cl})$ & $\mathrm{AOR}^{\mathrm{c}}(95 \% \mathrm{Cl})$ \\
\cline { 2 - 3 } & Yes No & &
\end{tabular}

\begin{tabular}{|c|c|c|c|c|}
\hline \multicolumn{5}{|c|}{ Counseling about EBF } \\
\hline Yes & 304 & 43 & $3.8(1.4,10.1)$ & $5.1(1.4,18.2)^{* *}$ \\
\hline No & 13 & 7 & 1 & 1 \\
\hline \multicolumn{5}{|c|}{ History of obstetric problem } \\
\hline Yes & 137 & 37 & 1 & 1 \\
\hline No & 180 & 13 & $3.7(1.9,7.3)$ & $3.4(1.3,8.9)^{* *}$ \\
\hline \multicolumn{5}{|l|}{ Decision to BF } \\
\hline Yes & 290 & 35 & $4.6(2.2,9.5)$ & $1.6(0.5,5.2)$ \\
\hline No & 27 & 15 & 1 & 1 \\
\hline \multicolumn{5}{|l|}{ Support to BF } \\
\hline Yes & 288 & 30 & $6.6(3.3,13.1)$ & $3.7(1.3,10.5)^{* *}$ \\
\hline No & 29 & 21 & 1 & 1 \\
\hline \multicolumn{5}{|c|}{ History of infanthood illness } \\
\hline Yes & 100 & 32 & 1 & 1 \\
\hline No & 217 & 18 & $3.9(2.1,7.2)$ & $1.45(0.6,3.6)$ \\
\hline \multicolumn{5}{|l|}{ Colostrum given } \\
\hline Yes & 262 & 30 & $3.5(1.8,6.5)$ & $1.92(0.7,5.3)$ \\
\hline No & 55 & 20 & 1 & 1 \\
\hline \multicolumn{5}{|l|}{ Place of delivery } \\
\hline Health institution & 312 & 45 & 1 & 1 \\
\hline home & 5 & 5 & $0.14(0.1,0.5)$ & $0.7(0.1,6.9)$ \\
\hline
\end{tabular}

${ }^{a}$ Exclusive breastfeeding

${ }^{\mathrm{b}}$ Crude Odds Ratio

'Adjusted Odds Ratio

**significant at a $p$-value of $<0.05$

they commonly perceived that their infants are not getting enough milk, and therefore they may fail to provide breast milk.

This study also affirmed that continuous exclusive breastfeeding rate was higher among mothers who received breastfeeding support. This finding was comparable with study conducted in Malawi [25] and research done in southern Ethiopia [24]. A similar finding was also reported from Swaziland [36], in which social support increased the ease of breastfeeding. In fact, sociocultural and economical support has a great role in obtaining the full benefits of breastfeeding, and the profound effect in maintaining optimal breastfeeding was noted in case of family support $[35,37]$.

Of the commonly documented determinants of EBF, maternal health care utilizations, such as antenatal care and institutional delivery were consistently reported by various studies $[18,20,22,25,40]$. But, these variables did not show significant association with continuous EBF in the current study. The discrepancy might be attributed to difference in the maternal health care utilization, in which almost all of the mothers had antenatal and postnatal follow up, and gave birth in a healthcare facility. However in most of the above study settings, utilization of maternal health services is sub-optimal.

The study tried to show the exclusive breastfeeding practice in a wider study area, particularly including the rural residents. However, it was not free from some of the limitations. Consequently, recall bias and social desirability bias are the possible limitation of the study.

\section{Conclusions}

In this study, a high proportion of HIV exposed infants were exclusively breastfed from the end of first week to 6 months of age. Breastfeeding counseling, breastfeeding support and experiencing an obstetric problem were the key factors associated with continuous exclusive breastfeeding. Therefore, intensifying breastfeeding counseling and support is essential to improve exclusive breastfeeding practices. Moreover, prompt diagnosis and treatment of obstetric problems should be encouraged.

\section{Abbreviations}

AIDS: Acquired immune deficiency syndrome; ANC: Antenatal care; AOR: Adjusted odds ratio; ART: Antiretroviral treatment; Cl: Confidence interval; HIV: Human immune deficiency virus; IYCF: Infant young child feeding; PMTCT: Prevention of Mother To Child Transmission; SPSS: Statistical package for social sciences; WHO: World Health Organization

\section{Acknowledgment}

We are indebted to the study participants, data collectors and supervisors for their commitment in the study.

Funding

No funding was obtained for this study.

Availability of data and materials

Data will be available upon request from the primary author

\section{Authors' contributions}

HG Conceived the study, coordinated data collection, performed the statistical analysis, and drafted the manuscript. MK participated in the design of the study and tool development, performed statistical analysis, and drafted the manuscript. AT participated in the design of the study and tool development, performed statistical analysis, and drafted and reviewed the manuscript. All authors read and approved the final manuscript.

\section{Competing interests}

Authors declare that they have no any conflict of interest.

\section{Consent for publication \\ Not applicable.}

\section{Ethics approval and consent to participate}

Ethical clearance was obtained from the Ethical Review Board of the University of Gondar (Ref. No/PH/2906/2016). A letter of permission was obtained from the Chief Executive Officers of the hospitals under study prior to the data collection. After the objective of the study was explained, verbal and written consent was secured from the mothers. The right of participants to withdraw from the study at any time without any precondition was disclosed unequivocally. Moreover, the confidentiality of information obtained was guaranteed by all data collectors and investigators by using code numbers rather than personal identifiers and by keeping the data locked. 


\section{Publisher's Note}

Springer Nature remains neutral with regard to jurisdictional claims in published maps and institutional affiliations.

\section{Author details}

${ }^{1}$ Gondar University Hospital, Gondar, Ethiopia. ${ }^{2}$ Department of Epidemiology and Biostatistics, College of Medicine and Health Sciences, Institute of Public Health, University of Gondar, Gondar, Ethiopia. ${ }^{3}$ Department of Human Nutrition, College of Medicine and Health Sciences, Institute of Public Health, University of Gondar, Gondar, Ethiopia.

Received: 16 June 2016 Accepted: 18 April 2017 Published online: 21 April 2017

\section{References}

1. Rollins NC, Bhandari N, Hajeebhoy N, Horton S, Lutter CK, Martines JC, Piwoz EG, Richter LM, Victora CG, Group TLBS. Why invest, and what it will take to improve breastfeeding practices? Lancet. 2016;387(10017):491-504.

2. Allen J, Hector D. Benefits of breastfeeding. N S W Public Health Bull. 2005; 16(4):42-6.

3. Kramer MS, Kakuma R. The optimal duration of exclusive breastfeeding. Protecting infants through human milk. Netherland: Springer Publication; 2004. p.63-77.

4. Quinn V, Guyon A, Martin L, Neka-Tebeb H, Martines J, Sagoe-Moses C. Nutrition and breastfeeding promotion. Opportunities for Africa's Newborns: Practical Data, Policy and Programmatic Support for Newborn Care in Africa PMNCH. Cape Town: Partnership for Maternal, Newborn and Child Health; 2006. p. 101-12

5. Coovadia HM, Rollins NC, Bland RM, Little K, Coutsoudis A, Bennish ML, Newell M-L. Mother-to-child transmission of HIV-1 infection during exclusive breastfeeding in the first 6 months of life. an intervention cohort study. Lancet. 2007;369(9567):1107-16.

6. WHO. Guidelines on HIV and Infant Feeding 2010: Principles and Recommendations for Infant Feeding in the Context of HIV and a Summary of Evidence. Geneva: WHO; 2010.

7. Raqa T. Breast is always best, even for HIV-positive mothers. Bull World Health Organ. 2010;88:9-10.

8. Semrau K, Kuhn L, Brooks DR, Cabral H, Sinkala M, Kankasa C, et al. Exclusive breastfeeding, maternal HIV disease, and the risk of clinical breast pathology in HIV-infected, breastfeeding women. Am J Obstet Gynecol. 2011;205(4):344.

9. Kafulafula UK, Hutchinson MK, Gennaro S, Guttmacher S, Kumitawa A. Exclusive breastfeeding prenatal intentions among HIV-positive mothers in Blantyre, Malawi: a correlation study. BMC Pregnancy Childbirth. 2013;13:201.

10. Cai X, Wardlaw T, Brown DW. Global trends in exclusive breastfeeding. Int Breastfeed J. 2012;7:1.

11. WHO: Malaria key facts: http://www.who.int/mediacentre/factsheets/fs094/en/ (Accessedon 21 Nov 2016)

12. Saka FJ. Factors influencing exclusive breastfeeding among HIV positive mothers at Ilala Municipality Dar es Salaam. Muhimbili University of Health and Allied Sciences. 2012.

13. Laar A, Ampofo W, Tuakli J, Quakyi I. Infant feeding choices and experiences of HIV-positive mothers from two Ghanaian districts. J AIDS HIV Res. 2009; 1(2):23-33.

14. Aishat U, David D, Olufunmilayo F. Exclusive breastfeeding and HIV/AIDS: a crossectional survey of mothers attending prevention of mother-to-child transmission of HIV clinics in southwestern Nigeria. Pan Afr Med J. 2015;21:309.

15. Okanda JO, Borkowf CB, Girde S, Thomas TK, Lecher SL. Exclusive breastfeeding among women taking HAART for PMTCT of HIV-1 in the Kisumu Breastfeeding Study. BMC Pediatr. 2014;14:280.

16. Maonga AR, Mahande MJ, Damian DJ, Msuya SE. Factors affecting exclusive breastfeeding among women in Muheza District Tanga Northeastern Tanzania. A mixed method community based study. Matern Child Health J. 2016;20(1):77-87.

17. Jepkogei KW. Determinants of adherence to exclusive breast feeding among HIV positive mothers attending child welfare clinic at Pumwani maternity hospital, Nairobi County, Kenya. Nairobi: Kenyatta University; 2013.

18. Ladzani R, Peltzer K, Mlambo MG, Phaweni K. Infant-feeding practices and associated factors of HIV-positive mothers at Gert Sibande, South Africa. Acta Paediatr. 2011;100(4):538-42.

19. Central Statistical Authority [Ethiopia] and ORC Macro: Ethiopia Demographic and Health Survey 2011. Addis Ababa. Maryland: Ethiopia and Calverton; 2011.
20. Demelew MZ, Abdeta G. Assessment of exclusive breastfeeding practice among HIV positive women in Addis Ababa. Afr J Midwifery Womens Health. 2014;8(1):14-20.

21. Bekere A, Garoma W, Beyene F. Exclusive breastfeeding practices of HIV positive mothers and its determinants in selected health institution of West Oromia, Ethiopia. J Nutr Food Sci. 2014;4:6.

22. Muluye $D$, Woldeyohannes $D$, Gizachew $M$, Tiruneh $M$. Infant feeding practice and associated factors of HIV positive mothers attending prevention of mother to child transmission and antiretroviral therapy clinics in Gondar Town health institutions, Northwest Ethiopia. BMC Public Health. 2012;12:240.

23. Matovu S, Kirunda B, Rugamba-Kabagambe G, Tumwesigye N, Nuwaha F. Factors influencing adherence to exclusive breastfeeding among HIV positive mothers in Kabarole District, Uganda. East Afr Med J. 2008;85(4):162-70.

24. Haile D, Belachew T, Birhanu G, Setegn T, Biadgilign S. Predictors of breastfeeding cessation among HIV infected mothers in southern Ethiopia: a survival analysis. Plos One. 2014;9(3):e90067.

25. Mataya R, Mathanga D, Chinkhumba J, Chibwana A, Chikaphupha K, Cardiello J. A qualitative study exploring attitudes and perceptions of HIV positive women who stopped breastfeeding at 6 months to prevent transmission of HIV to their children. Malawi Med J. 2013;25(1):15-9.

26. Aidam BA, Pérez-Escamilla R, Lartey A. Lactation counseling increases exclusive breastfeeding rates in Ghana. J Nutr. 2005:135(7):1691-5.

27. Maru Y, Haidar J. Infant feeding practice of HIV positive mothers and its determinants in selected health institutions of Addis Ababa, Ethiopia. Ethiop J Health Dev. 2009;23(2):107-14.

28. WHO. Infant and young child feeding: model chapter for textbooks for medical students and allied health professionals. Geneva: WHO Geneva; 2009.

29. Greiner T. Exclusive breastfeeding: measurement and indicators. Int Breastfeed J. 2014;9:18.

30. Banteyerga $\mathrm{H}$. Ethiopia's health extension program: improving health through community involvement. M MEDICC Review. 2011;13(3):46-9.

31. Wakwoya EB, Zewudie TA, Gebreslasie KZ. Infant feeding practice and associated factors among HIV positive mothers in Debre Markos Referral Hospital East Gojam zone, North West Ethiopia. Pan Afr Med J. 2016;24(300):2-13.

32. Balcha TT, Lecerof SS, Jeppsson AR. Strategic challenges of PMTCT program implementation in Ethiopia. Jint Assoc Phys AIDS Care. 2011;10(3):187-92.

33. Disha A, Rawat $R$, Subandoro A, Menon P. Infant and young child feeding (IYCF) practices in Ethiopia and Zambia and their association with child nutrition: Analysis of demographic and health survey data. Afr J Food Agric Nutr Dev. 2012;12(2):5895-914

34. Suryavanshi N, Jonnalagadda S, Erande AS, Sastry J, Pisal H, Bharucha KE, et al. Infant feeding practices of HIV-positive mothers in India. J Nutr. 2003;133: 1326-31.

35. Ikeako L, Ezegwui H, Nwafor M, Nwogu-lkojo E, Okeke T. Infant feeding practices among HIV-Positive Women in Enugu, Nigeria. Br J Med Med Res. 2015;8(1):61-8.

36. Shongwe MC, Mkhonta N. The experiences of HIV-positive mothers breastfeeding exclusively in Swaziland. Afr J Food Agric Nutr Dev. 2014; 15(1):9592-606.

37. Arora S, Mcjunkin C, Wehrer J, Kuhn P. Major factors influencing breastfeeding rates: Mother's perception of father's attitude and milk supply. Pediatrics. 2000; 106(5):e67.

38. Bilal NK, Herbst CH, Zhao F, Soucat A, Lemiere C. Health extension workers in Ethiopia: improved access and coverage for the rural poor. Yes Africa Can: Success Stories from a Dynamic Continent. 2011; 1-5.

39. Zanardo V, Svegliado G, Cavallin F, Giustardi A, Cosmi E, Litta P, Trevisanuto D. Elective cesarean delivery: does it have a negative effect on breastfeeding? Birth. 2010;37(4):275-9.

40. Mekuria G, Edris M. Exclusive breastfeeding and associated factors among mothers in Debre Markos, Northwest Ethiopia: a cross-sectional study. Int Breastfeed J. 2015;10:1 